\title{
THEASSOCIATED MENISCAL TEARS AND ASSOCIATED RISK FACTORS IN CONCOMITANT ACL INJURIES OF THE KNEE: A RETROSPECTIVE ANALYSIS
}

\author{
Kalawar RPS, ${ }^{1 *}$ Pokharel $B,{ }^{1}$ Chaudhary $P^{2}$ Rijal $R^{2}$
}

\begin{abstract}
Affiliation
1. Associate Professor, Department of Orthopaedics, B.P. Koirala Institute of Health Sciences, Dharan, Nepal

2. Professor, Department of Orthopaedics, BP Koirala Institute of Health Sciences, Dharan, Nepal
\end{abstract}

\section{ARTICLE INFO}

Received : 14 March, 2020
Accepted : 16 April, 2020
Published : 30 June, 2020

(C) Authors retain copyright and grant the journal right of first publication with the work simultaneously licensed under Creative Commons Attribution License CC - BY 4.0 that allows others to share the work with an acknowledgment of the work's authorship and initial publication in this journal.

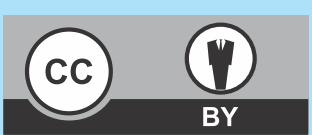

ORA 169

DOI: https://doi.org/10.3126/bjhs.v5i1.29639

* Corresponding Author

Dr. Rosan Prasad Shah Kalawar Associate Professor

Department of Orthopaedics

B.P. Koirala Institute of Health Science, Dharan

Email:docrosan@gmail.com

ORCID ID: https://orcid.org/0000-0002-3633-2360

\section{Citation}

Kalawar RPS, Pokharel B, Chaudhary P, Rijal R. The Associated Meniscal Tears and Associated Risk Factors in Concomitant ACL Injuries of The Knee: A Retrospective Analysis. BJHS 2020;5(1)11: 981-985.

\section{ABSTRACT}

\section{Introduction}

The pattern of meniscus tear has significant impact on subsequent rehabilitation and functional outcome as they are usually associated with ACL injury. Knowledge about associated meniscus tear helps to identify patients in the early post-traumatic phase.

\section{Objectives}

To study meniscus tear patterns and association between different tear patterns of meniscus in ACL injured subjects and to identify potential demographic and other associated risk factors.

\section{Methodology}

Routine arthroscopic findings database of 54 patients operated for primary ACL reconstruction from January 2017 to December 2018 was used to study associated tear of meniscus. Based on arthroscopic evaluation, cases weregrouped into meniscus having no tear, minor tear and majortear. Major tear included complete radial tears, root tears and unstable longitudinal tears including buckethandletears.

\section{Result}

Total arthroscopycases in the study duration were 124. Of those, $43 \%$ ( $n=54)$ under went $A C L$ reconstruction (ACLR) for torn ACL. Among the patients who under went ACLR, 58\% had not ear, $26 \%$ had minor tears, and $16 \%$ had major tears of the meniscus. There were significant differences between three groups for gender, age groups and mechanism of injury. Risk factors for major tears were male gender and age $<30$ years. Minor and major tears were associated with a contact injury.

\section{Conclusion}

Male, age $<30$ years and history of contact injury have high risks for having an associated meniscus tear. Early referral to magnetic resonance imaging and/or arthroscopy is recommended to allow meniscus repair in a timely manner.

\section{KEYWORDS}

Arthroscopy, anterior cruciate ligament, ACL, contact injury, meniscus. 


\section{INTRODUCTION}

Anterior cruciate ligament ( $\mathrm{ACL}$ ) injuries are commonly associated with meniscus tears with a prevalence rate of approximately $55 \%$ to $65 \%$. Associated meniscal tears are strong predictors for the development and progression of osteoarthritis (OA) of knee and worse patient reported outcomes in ACL reconstructed patients, especially if total or partial meniscectomy has been performed. ${ }^{6}$ Thus, preservation of meniscal tissue as much as possible and meniscus repair if indicated is increasingly preferred over meniscectomy combined with ACL reconstruction. ${ }^{7}$

Medial meniscus tears are more common with chronic $\mathrm{ACL}$ insufficiency while lateral meniscus tears are more prevalent in acute $\mathrm{ACL}$ injuries. ${ }^{8}$ The complexity of meniscus tears increases in the chronic stage and the tears become less repairable. ${ }^{9,10}$ The significance of meniscus repair is that the preservation of meniscus is associated with decreased risk for osteoarthritis compared to meniscectomy. ${ }^{6}$

Meniscus tears pattern observed in ACL-injured patients varies greatly and guides subsequent management and rehabilitation. Incomplete longitudinal tears and complete stable longitudinal tears affect minimally on knee joint health, thus can be left in situ. ${ }^{11-13}$ Bucket-handle tear, root tear, complete radial tear patterns are associated with major biomechanical bearings on knee health; so they should be repaired at the earliest possible to prevent accelerated joint degeneration. ${ }^{14-16}$

Tear patterns of the meniscus in ACL-injured subjects may be associated with variations in demographic and other risk factors such as gender, age, body weight, and injury mechanism. Study of such risk factors may help to identify major meniscal tears early. Very few studies have analyzed risk factors for different tear patterns of the meniscus in ACLinjured candidates. Thus, this study was conducted to refine current knowledge of risk factors for associated meniscus tears in ACL-injured candidates.

\section{METHODOLOGY}

\section{Study design}

Our study is a retrospective cohort design to study meniscus tear patterns and aims to identify the association between different tear patterns of the meniscus in ACL injured subjects and also to evaluate potential demographic and other risk factors associated.

The study protocol was approved by the institutional review committee of B.P. Koirala Institute of Health Sciences, Nepal (IRC number: IRC/1487/018). Patient record file and arthroscopy finding record proforma of all patient who had undergone arthroscopic ACL reconstruction from January 2017 to December 2018 was retrieved from medical record section of hospital. The relevant data was collected and organized to a masterchart.

Study subjects having Isolated meniscal injury, multiligamentous injuries or a history of previous surgery at the index knee were excluded from study.

Meniscus tear was grouped into three groups namely'no tear,' 'minor tear,' and 'major tear.'Minor meniscal tear included incomplete longitudinal tears or complete stable longitudinal tears not extending further than $1 \mathrm{~cm}$ in front of the popliteus tendon and radial or flap tears involving less than $75 \%$ of the meniscal width. ${ }^{11-13,16}$ Major tear included root tear (defined as avulsion of the meniscus root or complete radial tears within $1 \mathrm{~cm}$ from the bony insertion of the lateral meniscus), complete radial tears with transection of the meniscus ('radial split tears'), and unstable longitudinal tears including bucket-handle tears. ${ }^{14-17}$

The records were used to obtain demographic data and injury history with proper duration. Gender, age at surgery, height, weight, body mass index (BMI), type of injury, and mechanism of injury were considered for present study. Patient age was further analyzed by dividing the cohort into two age groups: $<30$ years and $>30$ years. Patients were divided into three BMI groups based on the classification of the World Health Organization: $<24.9 \mathrm{~kg} / \mathrm{m}^{2}$ (normal), $25-29.9 \mathrm{~kg} / \mathrm{m}^{2}$ (overweight), and $>30 \mathrm{~kg} / \mathrm{m}^{2}$ (obese). ${ }^{18}$ The circumstance in which the injury occurred was used to define the type of injury and was classified as high-impact sports-related, low-impact sports-related, and not sportsrelated injuries. Hunt Valley II (2005) definition was used to classify the mechanism of injury as non-contact mechanism or contact mechanism. ${ }^{19}$ When the forces applied to the knee joint resulted from the patients' own movements and did not involve contact with another person or object, the mechanism was assumed to be non-contact. A contact mechanism was assumed if an external force was directly applied to the knee joint or if an external force was applied to the patient but not directly to the injured knee.

\section{Statistical analysis}

SPSS software version 21.0 (IBM-SPSS, New York, USA) was used for Statistical analysis. The level of significance was set at $\mathrm{p}<.05$. Mean \pm standard deviation was used for continuous variables and confidence interval $(\mathrm{Cl})$ was set at $95 \%$. Categorical variables were reported as count and percentages.

Univariate analysis was performed by comparing the three study groups with regard to gender, age, age groups, height, weight, BMI, BMI groups, type of injury (high-impact sports, low-impact sports, and not sports related), and mechanism of injury (non-contact and con-tact). Level of significance, odds ratios (OR), and $95 \% \mathrm{Cls}$ were calculated for each variable.

\section{Sample size estimation}

This study considers 95\% confidence interval $(\mathrm{Cl})$ and $80 \%$ power to estimate the sample size. For this purpose, we had considered study by Michalitsis et al. in which $63 \%$ cases had meniscus injury in ACL deficient knee. ${ }^{5}$ The corrected sample size was 41 . However, we considered all cases of $A C L$ injury (total number 54) during last year.

\section{RESULTS}

A total of 124 knee arthroscopic procedures had been performed in the study. Of these, 54 (43\%) patients who underwent primary $\mathrm{ACL}$ reconstruction met our inclusion 
criteria and were included in the study. Our study population comprised of Thirty-six percent females and sixty four percent were males. Mean age was 29 (19-39) years, mean height was $175 \pm 9 \mathrm{~cm}$, mean weight was $75 \pm 15 \mathrm{~kg}$, and mean BMI was $25 \pm 5 \mathrm{~kg} / \mathrm{m}^{2}$. Sixty-seven percent of the patients were aged $<30$ years and the BMI was normal in $65 \%$. Most patients (67\%) injured their ACL during high-impact sports and a non-contact mechanism was found in $79 \%$.

Of the 54 included patients, $58 \%$ patients had isolated $\mathrm{ACL}$ tears, $26 \%$ had an associated minor meniscus tear, and $16 \%$ had an associated major meniscus tear. Table 1 shows detailed distribution of meniscus tear patterns and Table 2 shows patient characteristics of each group and the results of the univariate group comparison. Statistically significant differences between the 'no tear' and 'minor tear' groups were found for the mechanism of injury, with a higher proportion of contact injuries in the minor tear group $(p<0.05)$. Compared to patients with no tear, a significantly higher proportion of male patients $(p<0.001)$, patients $<30$ years $(p<0.01)$, and contact injuries $(p<0.001)$ were found in patients with major tears. In addition, contact injuries were significantly more common in patients with major tears as compared to patients with minor tears $(p<0.05)$.

Table1: Distribution of meniscus tear patterns ( $\mathrm{n}=54$ )
\begin{tabular}{|l|c|}
\hline Group & Percentage (\%) \\
\hline No tear & $\mathbf{5 8 \%}$ \\
\hline Minor tear & $\mathbf{2 6 \%}$ \\
\hline $\begin{array}{l}\text { Incomplete/Complete stable longitudinal } \\
\text { tear extending }<1 \mathrm{~cm} \text { in front of the } \\
\text { popliteus tendon }\end{array}$ & $20 \%$ \\
\hline $\begin{array}{l}\text { Radial or flap tear involving }<75 \% \text { of the } \\
\text { meniscal width }\end{array}$ & $6 \%$ \\
\hline Major tear & $16 \%$ \\
\hline Root tear & $9 \%$ \\
\hline Radial split tear & $4 \%$ \\
\hline Unstable longitudinal/bucket handle tear & $3 \%$ \\
\hline
\end{tabular}

Table 2: Univariate analysis (n=54)
\begin{tabular}{|l|c|c|c|c|}
\hline Variable & No tear & Minor tear & Major tear & P value \\
\hline & \multicolumn{5}{|c|}{ Gender } & $<0.05$ \\
\hline Female & $42 \%$ & $39 \%$ & $11 \%$ & \\
\hline Male & $58 \%$ & $61 \%$ & $89 \%$ & \\
\hline Age (years) & $\ldots$ & $28 \pm 10$ & $25 \pm 9$ & $>0.05$ \\
\hline \multicolumn{5}{|c|}{ Age groups (years) } \\
\hline$<30$ & $59 \%$ & $73 \%$ & $82 \%$ & $<0.05$ \\
\hline$>30$ & $41 \%$ & $27 \%$ & $18 \%$ & \\
\hline \multicolumn{5}{|c|}{ BMI (Kg/m ( $^{2}$ ) } \\
\hline$<24.9$ & $62 \%$ & $71 \%$ & $58 \%$ & $>0.05$ \\
\hline $25-29.9$ & $30 \%$ & $23 \%$ & $34 \%$ & \\
\hline$>30$ & $8 \%$ & $6 \%$ & $8 \%$ & \\
\hline \multicolumn{5}{|c|}{ Type of injury } \\
\hline $\begin{array}{l}\text { High-impact } \\
\text { sports }\end{array}$ & $65 \%$ & $64 \%$ & $77 \%$ & $>0.05$ \\
\hline $\begin{array}{l}\text { Low-impact } \\
\text { sports }\end{array}$ & $11 \%$ & $9 \%$ & $8 \%$ & \\
\hline $\begin{array}{l}\text { Not sports } \\
\text { related }\end{array}$ & $24 \%$ & $27 \%$ & $15 \%$ & \\
\hline \multicolumn{5}{|c|}{ Mechanism of injury } \\
\hline Non-contact & $92 \%$ & $73 \%$ & $43 \%$ & $<0.001$ \\
\hline Contact & $8 \%$ & $27 \%$ & $57 \%$ & \\
\hline
\end{tabular}

Table 3 shows the results of the multivariate logistic regression analysis. The sole independent risk factor for a minor tear was a contact mechanism with an OR of $4.3(95 \% \mathrm{Cl}$, 1.7-10.6). Independent risk factors for major tears were male gender (OR, 7.4; 95\% Cl, 1.9-27.6), age <30 years (OR, 5.8; 95\% Cl, 1.7-19.9), and a contact mechanism (OR, 18.5; $95 \% \mathrm{Cl}, 5.9-57.4)$.

\begin{tabular}{|c|c|c|c|c|c|c|}
\hline & \multicolumn{3}{|c|}{ Minor Tear } & \multicolumn{3}{|c|}{ Major Tear } \\
\hline & OR & $95 \% \mathrm{Cl}$ & P value & OR & $95 \% \mathrm{Cl}$ & $P$ value \\
\hline \multicolumn{7}{|l|}{ Gender } \\
\hline Female & \multicolumn{3}{|c|}{ Referent } & \multicolumn{3}{|c|}{ Referent } \\
\hline Male & 1.4 & $0.5-3.7$ & $>0.05$ & 7.4 & $1.9-27.6$ & $<0.05$ \\
\hline Age (years) & 0.9 & $0.9-1.0$ & $>0.05$ & 0.9 & $0.9-1.1$ & $>0.05$ \\
\hline \multicolumn{7}{|l|}{ Age groups (years) } \\
\hline$<30$ & 1.8 & $0.9-3.6$ & $>0.05$ & 5.8 & $1.7-19.9$ & $<0.05$ \\
\hline$>30$ & \multicolumn{3}{|c|}{ Referent } & \multicolumn{3}{|c|}{ Referent } \\
\hline \multicolumn{7}{|l|}{$B M I\left(K g / m^{2}\right)$} \\
\hline$<24.9$ & \multicolumn{3}{|c|}{ Referent } & \multicolumn{3}{|c|}{ Referent } \\
\hline $25-29.9$ & 0.3 & $0.1-1.4$ & $>0.05$ & 1.5 & $0.1-4.4$ & $>0.05$ \\
\hline$>30$ & 0.5 & $0.1-2.2$ & $>0.05$ & 1.4 & $0.1-2.8$ & $>0.05$ \\
\hline \multicolumn{7}{|l|}{ Type of injury } \\
\hline High-impact sports & 1.5 & $0.6-3.5$ & $>0.05$ & 0.6 & $0.2-2.3$ & $>0.05$ \\
\hline Low-impact sports & 1.1 & $0.3-4.2$ & $>0.05$ & 0.6 & $0.1-4.0$ & $>0.05$ \\
\hline Not sports related & \multicolumn{3}{|c|}{ Referent } & \multicolumn{3}{|c|}{ Referent } \\
\hline \multicolumn{7}{|l|}{ Mechanism of injury } \\
\hline Non-contact & \multicolumn{3}{|c|}{ Referent } & \multicolumn{3}{|c|}{ Referent } \\
\hline Contact & 4.3 & $1.7-10.6$ & $<0.05$ & 18.5 & $5.9-57.4$ & $<0.001$ \\
\hline
\end{tabular}

\section{DISCUSSION}

Identified risk factors for major meniscal tear were male gender $(O R=7.4)$ and age of $<30$ years $(O R=5.8)$ in this study. The strongest predictor for a major meniscal tear, however, was a contact injury mechanism with an OR of 18.5. Similarly, the sole risk factor for a minor meniscal tear was a contact injury mechanism with an OR of 4.3.

Many available studies evaluate risk factors for meniscus tears in $A C L$ injuries. However, most evaluate mainly the association of timing of surgery and meniscal tears. It has been shown that the incidence of medial meniscus tears increases with delayed surgery whereas the incidence of lateral meniscus tears is independent of the time interval from injury to $A C L$ reconstruction..$^{5,9,10,20,24-27}$ This result confirms that lateral meniscus tears occurat the time of initial injury and other factors than surgical delay must be responsible for lateral meniscus tears in ACL-injured subjects. However, only few studies have analyzed the association between different demographic and historical factors and meniscal tears. ${ }^{18}$ Kluczynski et al. examined the predictors of meniscal tears in 541 patients undergoing $\mathrm{ACL}^{18}$ The analyzed predictors included age, sex, BMI, mechanism of injury, type of injury, interval from injury to surgery, and instability episodes. The authors found that male sex predicted more lateral and medial meniscus tears, sportsrelated injuries predicted fewer medial meniscal tears, and more instability episodes predicted more medial meniscus tears. ${ }^{18}$ In a similar study, the association between meniscal injuries accompanying $A C L$ tears and the mechanism of injury, time from injury, activity level after the initial trauma, reinjury after the initial trauma, and BMI was analyzed in 293 patients. ${ }^{28}$ The authors concluded increasing time from injury, active daily life, and reinjury to be risk factors for 
meniscal injuries. ${ }^{28}$ A limitation of both studies is that meniscus tears were considered a binary finding (meniscus tear vs. no meniscus tear). No differentiation was made between different patterns of meniscus tears. However, the pattern of meniscus tears observed in ACL-injured subjects varies greatly and a differentiated perspective seems to be necessary because of their potential prognostic value. ${ }^{4,8}$ This study analyzed the association of different tear patterns of the meniscus and patient specific risk factors. Meniscus tear patterns regarded as major within this study were root tears, radial split tears, and unstable longitudinal tears including bucket-handle tears. These tear patterns dramatically alter the loading profile of the knee joint in biomechanical studies and are thought to promote the onset and rapid progression of $\mathrm{OA} \cdot{ }^{14-17}$ Repair of major meniscal tears at the time of $\mathrm{ACL}$ reconstruction should therefore be preferred over meniscectomy, since meniscus repair is associated with less cartilage degeneration and better clinical results. ${ }^{6,7}$ Unfortunately, meniscectomy was the most common method of treatment. Lateral meniscus tears were treated by meniscectomy in $71 \%$, by repair in $14 \%$, and left in situ in $14 \%$. Interestingly, performing surgery within 6 weeks was predictive of more lateral meniscal repairs. ${ }^{1}$ It is also found that higher meniscus healing rates occur in patients who underwent acute meniscus repair in conjunction with $\mathrm{ACL}$ reconstruction compared to delayed meniscus repair. ${ }^{29}$ These findings underline the importance of early identification of patients with major meniscal tears if repair is attempted. The findings of our present study imply that male patients, patients under the age of 30, and especially patients who sustained a contact injury are at high risk for an associated major lateral meniscus tear. We therefore recommend early referral of those patients to magnetic resonance imaging (MRI) and/or arthroscopy in order to allow meniscus repair in a timely manner.

Similar to our study, other studies have also found an association between male sex and an increased prevalence of concomitant meniscus tears. ${ }^{3,18,20,21,23}$ However, these studies did not differentiate between different meniscus tear patterns. In the present study, male sex was only predictive for major meniscal tears whereas gender distribution was similar among patients with no tear or a minor tear. This association may be explained by a lesser degree of $A C L$ resilience in females, leading to $A C L$ rupture

\section{REFERENCES}

1. Noyes FR, Barber-Westin SD. Treatment of meniscus tears during anterior cruciate ligament reconstruction. Arthroscopy. 2012;28: 123-30. doi:10.1016/j. arthro.2011.08.292.

2. Wyatt RW, Inacio MC, Liddle KD, Maletis GB. Factors associated with meniscus repair in patients undergoing anterior cruciate ligament reconstruction. Am J Sports Med. 2013;41:2766-71. doi:10.1177/ 0363546513503287.

3. Slauterbeck JR, Kousa P, Clifton BC, Naud S, Tourville TW, Johnson RJ, et al. Geographic mapping of meniscus and cartilage lesions associated with anterior cruciate ligament injuries. J Bone Joint Surg Am. 2009;91:2094-103. doi:10.2106/JBJS.H.00888. at smaller forces and thus less associated meniscal damage. ${ }^{21}$ A higher failure load of the ACL may also explain the observed higher risk for associated major lateral meniscus tears in younger patients.

There are several limitations of our study. This is a retrospective study so the validity of our findings is limited. The small sample size of 54 patients is relatively low for conducting an epidemiologic study. Only patients undergone $A C L$ reconstruction were evaluated and therefore the results may not allow generalization to all patients with an ACL tear. Differences in knee morphology, stratification according to medial or lateral meniscus or material properties of the meniscus were not examined which were many among many other factors that may predict the tear pattern.

\section{CONCLUSION}

Male sex, age $<30$ years, and a contact injury mechanism are independent risk factors for concomitant major meniscal tears among patients with a tear of the ACL. Patients with a contact injury mechanism have an approximately 18-fold increased risk for a major meniscus tear and is therefore necessary for an early referral to magnetic resonance imaging and /or arthroscopy in order to allow meniscus repair in a timely manner and avoid the outcomes of a late repair or missed meniscal tear.

\section{LIMITATIONS OF THE STUDY}

This study doesn't classify medial or lateral meniscus injury.

\section{ACKNOWLEDGEMENTS}

The authors acknowledge the medical record section for providing access to medical records and patient file.

\section{CONFLICT OF INTEREST}

The authors declare that they have no conflict of interest regarding this study.

\section{FINANCIAL DISCLOSURE}

The authors have not received financial grant from any company or pharmaceuticals. They have done this study voluntarily as a part of their academic career and interest.

4. Ghodadra N, Mall NA, Karas V, Grumet RC, Kirk S, McNickle AG, et al. Articular and meniscal pathology associated with primary anterior cruciate ligament reconstruction. J Knee Surg. 2013;26:185-93. doi:10.1055/s-0032-1327450.

5. Michalitsis S, Vlychou M, Malizos KN, Thriskos P, Hantes ME. Meniscal and articular cartilage lesions in the anterior cruciate ligament-deficient knee: correlation between time from injury and knee scores. Knee Surg Sports Traumatol Arthrosc. 2013. doi:10. 1007/s00167-013-2497-9.

6. Magnussen RA, Mansour AA, Carey JL, Spindler KP. Meniscus status at anterior cruciate ligament reconstruction associated with radiographic signs of osteoarthritis at 5- to 10-year follow-up: a systematic review. J Knee Surg. 2009;22:347-57.doi: 10.1055/s0030-1247773 
7. Shelbourne KD, Dersam MD. Comparison of partial meniscectomy versus meniscus repair for bucket-handle lateral meniscus tears in anterior cruciate ligament reconstructed knees. Arthroscopy. 2004;20:581-5. doi: 10.1016/j. arthro.2004.03.009.

8. Cipolla M, Scala A, Gianni E, Puddu G. Different patterns of meniscal tears in acute anterior cruciate ligament $(A C L)$ ruptures and in chronic ACL-deficient knees. Classification, staging and timing of treatment. Knee Surg Sports TraumatolArthrosc. 1995;3:130-4.doi: $10.1007 /$ bf01565470

9. Keene GC, Bickerstaff D, Rae PJ, Paterson RS. The natural history of meniscal tears in anterior cruciate ligament insufficiency. Am J Sports Med. 1993;21:672-9.doi: 10.1177/036354659302100506

10. Fok AW, Yau WP. Delay in ACL reconstruction is associated with more severe and painful meniscal and chondral injuries. Knee Surg Sports TraumatolArthrosc. 2013;21:928-33. doi:10.1007/s00167-0122027-1.

11. Pujol N, Beaufils P. Healing results of meniscal tears left in situ during anterior cruciate ligament reconstruction: a review of clinical studies. Knee Surg Sports TraumatolArthrosc. 2009;17:396-401. doi:10.1007/ s00167-008-0711-y.

12. Fitzgibbons RE, Shelbourne KD. "Aggressive" nontreatment of lateral meniscal tears seen during anterior cruciate ligament reconstruction. Am J Sports Med. 1995;23:156-9. DOI: 10.1177/036354659502300205

13. Shelbourne KD, Heinrich J. The long-term evaluation of lateral meniscus tears left in situ at the time of anterior cruciate ligament reconstruction. Arthroscopy. 2004;20:346-51. doi:10.1016/j.arthro. 2004.01.029.

14. Laprade CM, Jansson KS, Dornan G, Smith SD, Wijdicks CA, Laprade RF. Altered tibiofemoral contact mechanics due to lateral meniscus posterior horn root avulsions and radial tears can be restored with in situ pull-out suture repairs. J Bone Joint Surg Am. 2014;96:471-9. doi:10.2106/JBJS.L.01252.

15. Forkel P, Herbort M, Sprenker F, Metzlaff S, Raschke M, Petersen W. The biomechanical effect of a lateral meniscus posterior root tear with and without damage to the meniscofemoral ligament: efficacy of different repair techniques. Arthroscopy. 2014;30:833-40. doi:10.1016/j.arthro.2014.02.040.

16. Ode GE, Van Thiel GS, McArthur SA, Dishkin-Paset J, Leurgans SE, Shewman EF, et al. Effects of serial sectioning and repair of radial tears in the lateral meniscus. Am J Sports Med. 2012;40:1863-70. doi:10.1177/0363546512453291.

17. Schillhammer CK, Werner FW, Scuderi MG, Cannizzaro JP. Repair of lateral meniscus posterior horn detachment lesions: a biomechanical evaluation. Am J Sports Med. 2012;40:2604-9. doi:10.1177/ 0363546512458574.

18. Kluczynski MA, Marzo JM, Bisson LJ. Factors associated with meniscal tears and chondral lesions in patients undergoing anterior cruciate ligament reconstruction: a prospective study. Am J Sports Med. 2013;41:2759-65. doi:10.1177/0363546513503448.

19. Hewett TE, Shultz SJ, Griffin LY. Understanding and preventing noncontact ACL injuries. Champaign, IL: Human Kinetics; 2007.doi: 10.1177/0363546506286866

20. Chhadia AM, Inacio MC, Maletis GB, Csintalan RP, Davis BR, Funahashi TT. Are meniscus and cartilage injuries related to time to anterior cruciate ligament reconstruction? Am J Sports Med. 2011;39:1894-9. doi:10.1177/0363546511410380.

21. Piasecki DP, Spindler KP, Warren TA, Andrish JT, Parker RD. Intraarticular injuries associated with anterior cruciate ligament tear: findings at ligament reconstruction in high school and recreational athletes. An analysis of sex-based differences. Am J Sports Med. 2003;31:601-5.doi: 10.1177/03635465030310042101

22. Bowers AL, Spindler KP, McCarty EC, Arrigain S. Height, weight, and $B M I$ predict intra-articular injuries observed during $A C L$ reconstruction: evaluation of 456 cases from a prospective $\mathrm{ACL}$ database. Clin J Sport Med. 2005;15:9-13.doi: 10.1097/00042752200501000-00003

23. O'Connor DP, Laughlin MS, Woods GW. Factors related to additional knee injuries after anterior cruciate ligament injury. Arthroscopy. 2005;21:431-8. doi:10.1016/j.arthro.2004.12.004.

24. Tandogan RN, Taser O, Kayaalp A, Taskiran E, Pinar H, Alparslan B, et al. Analysis of meniscal and chondral lesions accompanying anterior cruciate ligament tears: relationship with age, time from injury, and level of sport. Knee Surg Sports Traumatol Arthrosc. 2004;12: 262-70. doi:10.1007/s00167-003-0398-z.

25. Murrell GA, Maddali S, Horovitz L, Oakley SP, Warren RF. The effects of time course after anterior cruciate ligament injury in correlation with meniscal and cartilage loss. Am J Sports Med. 2001;29:9-14. doi: 10.1177/03635465010290012001

26. Millett PJ, Willis AA, Warren RF. Associated injuries in pediatric and adolescent anterior cruciate ligament tears: does a delay in treatment increase the risk of meniscal tear? Arthroscopy. 2002;18: 955-9. doi: 10.1053/jars.2002.36114

27. Church S, Keating JF. Reconstruction of the anterior cruciate ligament: timing of surgery and the incidence of meniscal tears and degenerative change. J Bone Joint Surg (Br). 2005;87:1639-42. doi:10.1302/0301-620X.87B12.16916.

28. Chen G, Tang X, Li Q, Zheng G, Yang T, Li J. The evaluation of patientspecific factors associated with meniscal and chondral injuries accompanying $A C L$ rupture in young adult patients. Knee Surg Sports TraumatolArthrosc. 2013. doi:10.1007/s00167-013-2718-2.

29. Tenuta JJ, Arciero RA. Arthroscopic evaluation of meniscal repairs. Factors that effect healing. Am J Sports Med. 1994;22:797-802.doi: $10.1177 / 036354659402200611$ 